\title{
Key quality factors at urban interchanges
}

1 Giulia Dell'Asin MSc PhD Candidate, Traffic Planning, SBB CFF FFS, Lucerne, Switzerland

2 Andrés Monzón PhD

Professor, Civil Engineering Transport Department, Universidad Politécnica de Madrid, Madrid, Spain
3 María Eugenia Lopez-Lambas PhD

Associate Professor, Civil Engineering Transport Department, Universidad Politécnica de Madrid, Madrid, Spain


Quality of service should not be overlooked in public transport planning and policy making, as it influences modal shift from car use to more sustainable means. Little research has been conducted on the quality of public transport interchanges from the perspective of current travellers (i.e. perceived quality). This work thus aimed to identify key quality factors at urban interchanges through an exploratory approach (multiple correspondence analysis) that provides novel elements for further investigation. The methodology was applied at interchanges in Madrid and Gothenburg and the data used in the analysis were collected through customer satisfaction surveys conducted in 2011. The analysis identified five key quality factors per interchange. Ticketing plays a key role at both interchanges while physical and environmental issues emerged at Avenida de América in Madrid, and services, temporal issues and interconnectivity characterise Gothenburg central station. Compared with other quality aspects, classical issues such as safety/security and information are not perceived as important by intermodal travellers.

\section{Introduction}

Over the last decade, major efforts have been made to increase modal shift from cars to public transport, leading to a reduction of the negative effects of the growth in car use, such as traffic congestion and air and noise pollution (EC, 2011). The current European strategy aims to improve this trend and ensure seamless door-to-door journeys other than by car (Hine and Scott, 2000).

The quality of public transport services strongly influences modal shifts to more sustainable means of transport and has an indirect influence on demand for public transport (Paulley et al., 2006). Quality of service is thus highly relevant to public transport systems and therefore should not be overlooked in transport policies. This concept considers both managerial and customer perspectives (Parasuraman et al., 1985) and is incorporated into European regulation on public transport service, which stresses the importance of focusing on passengers' expectations and perceptions (Aenor, 2003). Recent studies have identified quality attributes that characterise a public transport system according to passengers' perspective (Beirão and Sarsfield, 2007; De Oña et al., 2012; Dell'Olio et al., 2010).

According to Currie (2005), the transfer between one public transport vehicle and another is perceived as a great penalty. This includes all the time spent walking or waiting to complete a transfer, in addition to the effects of disruption. Public transport interchanges - the nodes of a transport system where passengers transfer between public transport means and between these and cars or other means of transportation (EC, 2009) - can help to reduce this penalty by facilitating transfers and minimising disruptions.

However, efficiency of intermodal points cannot be achieved if stakeholders neglect the issue of quality, from planning to management. Currently, the most critical issue is that the management of a single interchange zone may fall within the responsibility of several organisations (Lopez-Lambas and Monzón, 2010; Vassallo et al., 2012). This is particularly difficult when shortdistance trips are connected to long-distance trips and poor coordination among stakeholders prevents the possibility of seamless travel chains (Hermes, 2011).

Even though there are different infrastructure typologies that can be defined as 'transport interchanges' (bus/metro/rail stations, park \& ride terminals, airports, etc.), there are common guidelines and good practices that have been developed for the design of transport interchanges (Blow, 2005; Mulroy, 2001). Quality at interchanges translates into a reliable supply and interconnectivity 
of services, adequate accessibility for all users, clear information, integrated ticketing systems, safety/security, services, functional use of available space and transfer distances, and attention to environmental and architectural issues (Bowers, 2011).

A review of the relevant literature indicates that researchers have mainly focused on the topic of quality linked to a single means of transportation (trips). Relatively little research has been conducted on the quality of service at interchanges as perceived by passengers (Dell'Asin, 2011).

The objective of this paper is to identify key quality factors (KQFs) at urban interchanges, according to the needs and perceptions of intermodal travellers. The proposed methodology is based on customer satisfaction surveys carried out at two European urban interchanges where both short- and long-distance trips are interconnected - Avenida de América interchange in Madrid and Gothenburg central station. The methodological approach is presented in Section 2 and Section 3 describes the case studies. Section 4 presents the surveys conducted at the interchanges and the main findings on key quality factors (KQFs) are reported in Section 5. Finally, conclusions are summarised in Section 6.

\section{Methodology}

A brief overview of approaches used to assess travellers' perceptions of public transport service is presented in this section, followed by a description of the methodology in this study.

\subsection{Quantitative methods to assess perceived quality}

Mathematical (statistical) approaches have been developed to better understand the data collected through passenger satisfaction surveys and to assess travellers' perceptions of public transport services. A review of the available literature reveals that researchers commonly implement regression analyses to identify quality determinants. Logit regression is generally preferred to multiple regression modelling because the quality attributes are usually treated as ordinal-scale variables with five or ten categories (Dell'Asin, 2011).

Morfoulaki et al. (2007) implemented multinomial logistic regression to estimate the probability of very satisfied customers, showing that customer satisfaction can be improved by focusing on specific issues (waiting times, frequency, etc.). Eboli and Mazzulla (2008) used the same approach to evaluate the importance of service quality attributes to global customer satisfaction and calibrated the models through stated preference data. Ordinal (ordered logit and probit) models have also been applied, using data from revealed preference surveys to identify which variables had the most influence on the overall perception of service quality (Rojo et al., 2011). Other studies have used structural equation modelling (Eboli and Mazzulla, 2007) or the critical incident approach, which analyses the influence of negative critical incidents (i.e. cases that are particularly satisfying or dissatisfying) on customers' overall satisfaction (Friman, 2004).

\subsection{Multiple correspondence analysis}

The present study applied multiple correspondence analysis (MCA) to data obtained through customer satisfaction surveys that were designed to gain an understanding of the level of satisfaction of customers with a series of quality attributes at interchanges.

The implementation of MCA allows the exploration of latent constructs with regard to satisfaction of quality attributes, thus identifying so-called key quality factors. MCA is an exploratory multi-variate statistical technique for categorical data. It attempts to reduce the variability in a model by calculating the minimum number of factors that can explain the most variability (inertia) in the model (Hair et al., 2010). MCA works in a similar way to principal components analysis (PCA), the most common statistical technique to extract from a set of variables a reduced set of factors that accounts for most of the variance in the variables. However, PCA extracts the variables that explain the largest amount of variance in the dataset, whereas MCA also shows the 'correspondence', or association, among the categories of variables.

This association is graphically represented through perceptual plots, whose interpretation is not always intuitive, since MCA uses the chi-squared distance rather than Euclidean distance between the points. In practice, perceptual plots represent the association of the categories according to the dimensions (factors) extracted in the analysis. The categories of the variables that most influence the calculation of the axes, representing the dimensions, are those that have the higher contribution and are at the extreme position.

This multi-variate statistical method was chosen for this study for two main reasons (Greenacre, 2007) - it assumes that the data are discrete variables and, being a non-parametric statistical method, it needs no special statistical assumptions.

MCA was performed on the quality attributes of customer satisfaction surveys (Section 4) carried out in two European case studies (Section 3). The data were analysed independently for each case study using Statistical Package for the Social Sciences (SPSS) Statistics, v.19.0. It was decided to retain the dimensions that accounted for approximately $80 \%$ of the variance.

\section{Case studies}

The methodology was applied to two case studies. These case studies are good examples of passenger intermodality and represent different typologies of an urban interchange - Avenida de América in Madrid as an urban interchange mainly related to the metro service and Gothenburg central as a railway station. They both embrace interconnections among short- and longdistance trips to/from the terminal and both public and private transport means.

\subsection{Avenida de América interchange}

Avenida de América interchange (Figure 1) is located in the north east of Madrid, Spain. Some 152000 passengers transfer daily 



Figure 1. Avenida de América interchange

through the interchange, which is part of the Madrid regional plan for public transport interchanges (CRTM, 2010) for achieving the goal of seamless mobility between long and regional journeys. The interchange came into service in 2000. Comprising four underground floors, it offers metro services as well as national, regional and urban bus services. In 2012 it was revamped to improve air conditioning, safety/security facilities, platform screens and transfer walkways.

\subsection{Gothenburg central station}

Gothenburg central station (Figure 2) is the major national passenger transport hub in the south west of Sweden. It is located in the central area of Gothenburg, with plans to develop into an attractive communications hub and regional centre (City of Gothenburg, 2012). About 101000 passengers go through the station every day to use tram, urban and international rail and bus services. The complex consists of three buildings - the old restored railway station (1856-1857), the new meeting place (2003) and the relatively new bus terminal (1996). Together, they constitute a travel centre with shops, cafes, restaurants, offices and a hotel.

\section{Data}

Customer satisfaction surveys were carried out as part of the Hermes (High Efficient and Reliable arrangeMEnts for croSs-
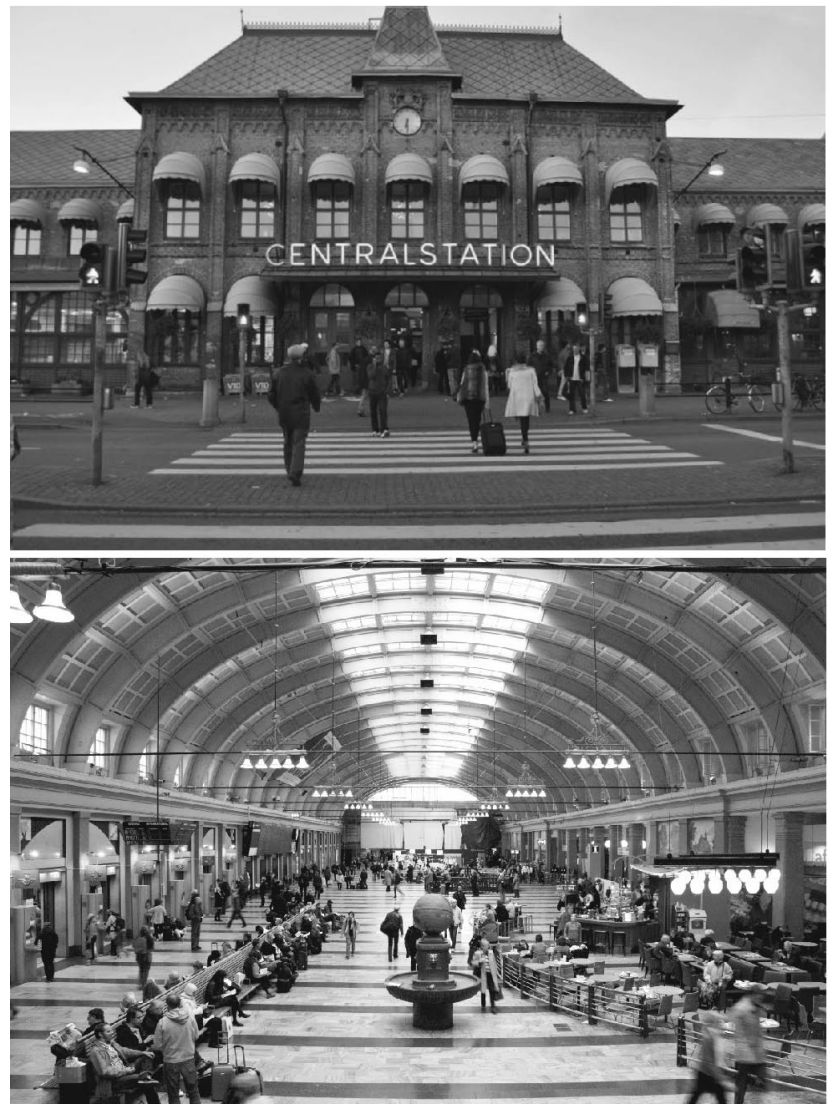

Figure 2. Gothenburg central station

modal transport) project of the EU 7th Framework Programme (Hermes, 2011). The questionnaire used consisted of different modules and respondents were asked to answer questions on socio-demographic profile and travel patterns (age, gender, purpose, means of transportation, waiting time, familiarity with the interchange, etc.) and to rate their satisfaction of 26 quality attributes, grouped into five categories (Table 1), on a Likert scale ranging from positive (5) to negative (1) values.

The surveys were based on random sampling, with every element of the population having a known and equal probability of selection. The sample size, calculated according to the Bartlett et al. (2001) formulation for a finite population, was 383 travellers per case study to achieve a $95 \%$ interval of confidence. In the end, the effective sample size was 379 in Madrid and 508 in Gothenburg, leading to a lower margin of error for the Swedish case study $( \pm 4 \cdot 0 \%)$. The surveys, carried out in April and May 2011 at rush hour on working days, addressed travellers over the age of 15 who passed through the urban interchanges (at bus stops, railway platforms, terminal halls, etc.).

According to the questionnaires collected, travellers at Avenida de América are mainly female (56\%) with the majority of respondents aged 21 to $35(51 \%)$. They mainly reach the interchange by metro $(66 \%)$ and leave it by long-distance bus 


\begin{tabular}{|c|c|c|}
\hline Category & Label & Description \\
\hline \multirow[t]{3}{*}{ Supply } & Su1 & Coordination of timetables between different transport means \\
\hline & Su2 & Possible travel connections between origin and destination \\
\hline & Su3 & Possibility of combining different transport means \\
\hline \multirow[t]{4}{*}{ Time } & Ti1 & Punctuality of transport operators \\
\hline & Ti2 & Total time for check-in services (at a counter with personnel) \\
\hline & Ti3 & Total time spent for baggage drop \\
\hline & Ti4 & Total waiting time \\
\hline \multirow[t]{3}{*}{ Space } & Sp1 & Space at the station (not overcrowded) \\
\hline & Sp2 & Total seating capacity \\
\hline & Sp3 & Access to luggage storage \\
\hline \multirow[t]{6}{*}{ Information } & $\ln 1$ & Information signs \\
\hline & $\ln 2$ & Availability of staffed information counters \\
\hline & $\ln 3$ & Possibility of buying different types of tickets (ticketing machines) \\
\hline & $\ln 4$ & Possibility of buying different types of tickets (at a counter with personnel) \\
\hline & $\ln 5$ & Personnel's service at ticket counters \\
\hline & $\ln 6$ & Possibility of rescheduling tickets \\
\hline \multirow[t]{10}{*}{ Services } & Se1 & Shopping facilities \\
\hline & $\mathrm{Se} 2$ & Additional services (banking, postal services) \\
\hline & $\mathrm{Se} 3$ & Access to toilets \\
\hline & Se4 & Cleanliness \\
\hline & Se5 & Access to internet \\
\hline & Se6 & Access to lounges/waiting rooms \\
\hline & Se7 & Ventilation \\
\hline & Se8 & Safety/security \\
\hline & Se9 & Baby care facilities, play areas \\
\hline & Se10 & Access to parking spaces (car, bicycles) \\
\hline
\end{tabular}

Table 1. Quality attribute variables used in Hermes customer satisfaction surveys

(92\%). The most common purpose of the intermodal journey is private issues (visiting family/friends) (64\% of respondents); study was the least common purpose $(4 \%)$. The travellers interviewed generally spend a significant amount of time in Avenida de América (58\% spend more than $45 \mathrm{~min}$ ) and are quite or very familiar with it $(68 \%)$.

In Gothenburg central station, travellers are mainly young women (65\%), with the most common age groups being $15-20$ years and 21-35 years (together accounting for $60 \%$ of respondents). The travellers interviewed mainly reach the terminal by long-distance train $(37 \%)$ or tram/urban bus (together accounting for 38\%) and mainly leave it by long-distance train $(73 \%)$. Private purposes (shopping) are the most common reason for travelling (58\%), followed by business $(23 \%)$. Time spent in the terminal is generally high, with $42 \%$ of interviewed travellers spending more than 45 min there. Familiarity with the terminal is also good, with $76 \%$ of the sample being quite or very familiar with it.

\section{Results}

This section presents the main findings from implementation of MCA to the two case studies. KQFs were labelled to better understand the outputs and the underlying constructs of quality. Interpretation of the factors was possible by looking at the measures of discrimination generated by SPSS, representing the degree of association between each quality attribute and each dimension. Only symmetrical perceptual plots of the first two dimensions, which together account for the largest amount of inertia, are reported in this paper.

\subsection{Avenida de América interchange}

Multiple correspondence analysis was performed on 21 quality attributes, since five variables (Su1, Ti2, In1, Se6, Se10) could not be integrated in the analysis due to a large amount of missing data (the questionnaires could not be completed because travellers interrupted the interview or had to catch their next transport connection). Table 2 shows the five dimensions that were retained in the analysis of Avenida de América, accounting for $79 \%$ of the total variance explained by the model.

Looking at the measures of discrimination in Table 3 , it can be observed that variables representing supply aspects are weakly associated with all the axes and are consequently perceived as less important by travellers. 


\begin{tabular}{lcccc}
\hline \multirow{2}{*}{ Dimension } & Cronbach's $\alpha$ & \multicolumn{3}{c}{ Variance accounted for } \\
\cline { 3 - 5 } & & $\begin{array}{c}\text { Total } \\
\text { (singular value) }\end{array}$ & Inertia & $\begin{array}{c}\text { Proportion of } \\
\text { inertia: \% }\end{array}$ \\
\hline 1 & 0.812 & 4.414 & 0.210 & 21.020 \\
2 & 0.768 & 3.726 & 0.177 & 17.743 \\
3 & 0.743 & 3.419 & 0.163 & 16.280 \\
4 & 0.679 & 2.832 & 0.135 & 13.486 \\
5 & 0.582 & 2.245 & 0.107 & 10.692 \\
Total & - & 20.840 & 0.992 & - \\
Mean & 0.697 & 2.977 & 0.142 & 14.177 \\
Table 2. MCA output: Avenida de América, Madrid & & \\
\hline
\end{tabular}

\begin{tabular}{|c|c|c|c|c|c|c|}
\hline \multirow{2}{*}{$\begin{array}{l}\text { Quality } \\
\text { attribute }\end{array}$} & \multicolumn{5}{|c|}{ Dimension } & \multirow[t]{2}{*}{ Average } \\
\hline & 1 & 2 & 3 & 4 & 5 & \\
\hline Su2 & 0.141 & 0.034 & 0.089 & 0.041 & 0.022 & 0.065 \\
\hline Su3 & $0 \cdot 138$ & 0.149 & 0.127 & 0.119 & 0.121 & 0.131 \\
\hline Ti1 & $0 \cdot 197$ & 0.062 & 0.181 & 0.084 & 0.092 & 0.123 \\
\hline Ti3 & 0.208 & 0.253 & 0.111 & 0.119 & 0.067 & 0.152 \\
\hline Ti4 & $0 \cdot 197$ & 0.084 & 0.229 & 0.045 & 0.050 & 0.121 \\
\hline Sp1 & $0 \cdot 324$ & 0.169 & 0.373 & 0.121 & $0 \cdot 194$ & 0.236 \\
\hline Sp2 & 0.352 & 0.118 & 0.213 & 0.083 & 0.204 & 0.202 \\
\hline Sp3 & $0 \cdot 250$ & 0.055 & 0.110 & 0.098 & 0.126 & 0.128 \\
\hline $\ln 2$ & 0.093 & 0.033 & 0.167 & 0.192 & 0.102 & 0.117 \\
\hline $\ln 3$ & 0.098 & 0.500 & 0.065 & 0.332 & 0.045 & 0.208 \\
\hline $\ln 4$ & $0 \cdot 191$ & 0.067 & 0.120 & 0.315 & 0.015 & 0.142 \\
\hline $\ln 5$ & 0.223 & 0.097 & 0.117 & 0.394 & 0.051 & 0.177 \\
\hline $\ln 6$ & 0.094 & 0.500 & 0.071 & 0.337 & 0.035 & 0.208 \\
\hline Se1 & $0 \cdot 188$ & 0.146 & 0.170 & 0.035 & 0.097 & 0.127 \\
\hline $\mathrm{Se} 2$ & $0 \cdot 178$ & 0.203 & 0.130 & 0.152 & 0.060 & 0.144 \\
\hline $\mathrm{Se} 3$ & $0 \cdot 201$ & 0.046 & 0.255 & 0.067 & 0.073 & 0.120 \\
\hline Se4 & 0.298 & 0.098 & 0.208 & 0.016 & 0.280 & $0 \cdot 180$ \\
\hline Se 5 & $0 \cdot 196$ & 0.634 & 0.154 & 0.133 & 0.129 & 0.249 \\
\hline Se7 & $0 \cdot 374$ & 0.047 & 0.339 & $0 \cdot 109$ & 0.258 & 0.225 \\
\hline $\mathrm{Se} 8$ & 0.228 & 0.089 & 0.182 & 0.018 & 0.065 & 0.116 \\
\hline Se9 & $0 \cdot 244$ & 0.340 & 0.008 & 0.021 & 0.158 & $0 \cdot 154$ \\
\hline Total & $4 \cdot 414$ & $3 \cdot 726$ & $3 \cdot 419$ & $2 \cdot 832$ & $2 \cdot 245$ & $3 \cdot 327$ \\
\hline $\begin{array}{l}\text { Variance: } \\
\%\end{array}$ & 21.020 & $17 \cdot 743$ & $16 \cdot 280$ & $13 \cdot 486$ & $10 \cdot 690$ & $15 \cdot 844$ \\
\hline
\end{tabular}

Table 3. Measures of discrimination: Avenida de América

Dimension 1, which accounts for the most variance in the model (21\%), is mainly related to space at the station (Sp1), total seating capacity (Sp2) and ventilation (Se7) within the interchange. KQF1 was thus labelled 'physical', mainly representing aspects of the physical space and the environmental conditions.
The second dimension relates to the possibility of buying different types of tickets at ticketing machines (In3), the availability to reschedule tickets (In6) and access to internet (Se5). KQF2, mainly representing issues that involve the use of machines or PCs, laptops, smartphones and so on, was labelled 'technology',

Dimension 3, similarly to dimension 1, relates to physical and environmental aspects (Sp1, Se7), with a strong association to access to toilets $(\mathrm{Se} 3) . \mathrm{KQF} 3$ is thus associated with issues that create a pleasant and healthy space to stay and was labelled 'comfort'.

The fourth dimension mainly relates to the possibility of buying different types of tickets either at ticketing machines (In3) or from staff at counters (In4), personnel service (In5) and the availability to reschedule tickets (In6). KQF4 was labelled 'ticketing'.

The fifth dimension is associated with cleanliness of the entire terminal ( $\mathrm{Se} 4)$ and ventilation (Se7). This is another factor associated with environmental and comfort issues: KQF5 was labelled 'wellbeing'.

Figure 3 illustrates the perceptual plot of dimensions 1 and 2, which together account for the large amount of inertia (39\%), detecting structural relationships between the categories of the ordinal-scale variables (quality attributes). Regarding the axis of the first dimension, the lowest ratings of satisfaction fall into the negative side, while the highest ratings fall into the positive area. Therefore, KQF1 (physical) represents extreme satisfactions of quality: very low (1) or very high (5). As regards the axis of the second dimension, the projections of the point (the categories) are plotted near the origin, indicating that there is no clear distinction between the opposite poles of the axis. In this case, the interpretation of the axis is hazardous and for KQF2 (technology) it is not possible to identify a clear satisfaction pattern.

Regarding the other dimensions, only a summary is given here, indicating the different levels of satisfaction associated 


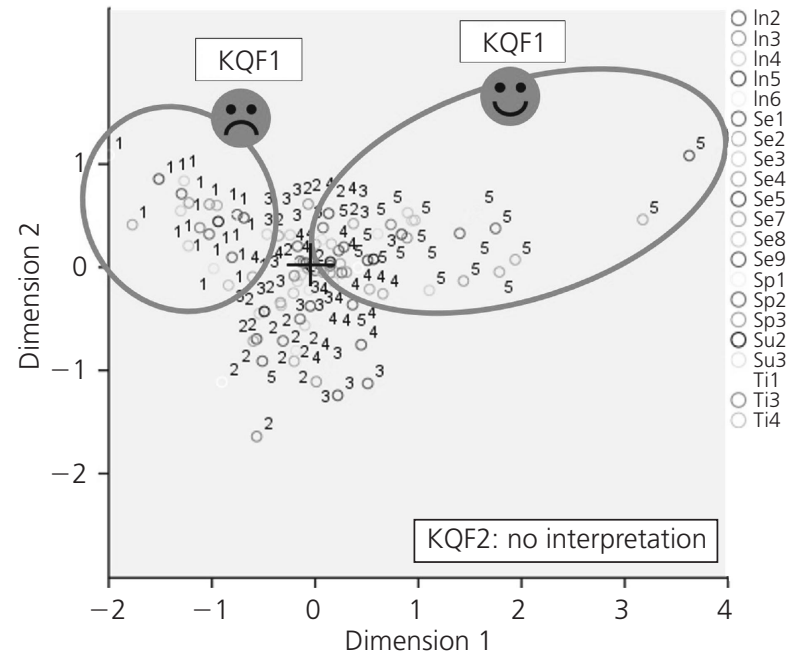

Figure 3. Avenida de América - perceptual plot KQF1-KQF2

with the axes (Table 4). Travellers at Avenida de América interchange either strongly dislike or are very enthusiastic about the factors and only KQF4 (ticketing) was skewed to low values.

\subsection{Gothenburg central station}

For the Gothenburg case study, MCA was performed on 25 quality attributes - only one variable (In5) could not be considered due to missing data. Table 5 shows the five dimensions used in the analysis of Gothenburg central station, accounting for $80 \%$ of the total variance explained by the model.

Table 6 lists the measures of discrimination. It can be observed that variables related to physical aspects have low values, meaning they contribute less to forming the dimensions and are therefore perceived as less important by travellers.

Dimension 1, which explains the most variance in the model $(22 \%)$, is mainly related to the total time spent waiting for baggage drop (Ti3), the total waiting time (Ti4), the availability of staffed information counters (In2) and additional services (Se2). KQF1 was thus labelled 'time', mainly representing temporal aspects and issues related to saving time (e.g. banking services or the availability of getting information directly from somebody).

The second dimension relates to several quality attributes representing service issues. It is mainly associated with additional

\begin{tabular}{|c|c|c|c|c|}
\hline & \multirow{2}{*}{$\begin{array}{l}\text { Significant quality } \\
\text { attributes }\end{array}$} & \multirow[t]{2}{*}{ Label } & \multicolumn{2}{|c|}{ Level of satisfaction } \\
\hline & & & $\begin{array}{l}\text { Negative axis } \\
\text { of perceptual } \\
\text { plot }\end{array}$ & $\begin{array}{l}\text { Positive axis } \\
\text { of perceptual plot }\end{array}$ \\
\hline KQF1 & Sp1, Sp2, Se7 & Physical & Very low & Very high \\
\hline KQF2 & $\ln 3, \ln 6, \operatorname{se} 5$ & Technology & \multicolumn{2}{|c|}{ Interpretation hazardous } \\
\hline KQF3 & Sp1, Se3, Se7 & Comfort & High & Very low/very high \\
\hline KQF4 & $\ln 3, \ln 4, \ln 5, \ln 6$ & Ticketing & Very low & Medium \\
\hline KQF5 & Se4, Se7 & Wellbeing & Low & Very low/very high \\
\hline
\end{tabular}

Table 4. Summary of KQFs for Avenida de América

\begin{tabular}{lcccc}
\hline Dimension & Cronbach's $\alpha$ & \multicolumn{3}{c}{ Variance accounted for } \\
\cline { 3 - 5 } & & $\begin{array}{c}\text { Total } \\
\text { (singular value) }\end{array}$ & Inertia & $\begin{array}{c}\text { Proportion of } \\
\text { inertia: \% }\end{array}$ \\
\hline 1 & 0.892 & 6.982 & 0.279 & 21.902 \\
2 & 0.829 & 4.893 & 0.196 & 19.611 \\
3 & 0.793 & 4.181 & 0.167 & 16.780 \\
4 & 0.671 & 2.810 & 0.112 & 11.222 \\
5 & 0.639 & 2.590 & 0.104 & 10.453 \\
Total & - & 21.456 & 0.858 & - \\
Mean & 0.764 & 4.2912 & 0.171 & 15.993
\end{tabular}

Table 5. MCA output: Gothenburg central station 


\begin{tabular}{|c|c|c|c|c|c|c|}
\hline \multirow{2}{*}{$\begin{array}{l}\text { Quality } \\
\text { attribute }\end{array}$} & \multicolumn{5}{|c|}{ Dimension } & \multirow[t]{2}{*}{ Average } \\
\hline & 1 & 2 & 3 & 4 & 5 & \\
\hline Su1 & 0.267 & 0.170 & 0.158 & 0.380 & 0.205 & 0.236 \\
\hline Su2 & 0.317 & 0.137 & 0.134 & 0.278 & 0.194 & $0 \cdot 212$ \\
\hline Su3 & 0.311 & 0.237 & 0.186 & 0.289 & 0.224 & 0.250 \\
\hline Ti1 & 0.211 & 0.068 & 0.096 & 0.080 & 0.095 & $0 \cdot 110$ \\
\hline Ti2 & 0.226 & 0.049 & 0.147 & 0.083 & 0.155 & $0 \cdot 132$ \\
\hline Ti3 & 0.322 & 0.113 & 0.135 & $0 \cdot 218$ & $0 \cdot 161$ & $0 \cdot 190$ \\
\hline Ti4 & 0.351 & 0.216 & 0.110 & 0.363 & 0.088 & 0.226 \\
\hline Sp1 & 0.286 & 0.173 & 0.040 & 0.078 & 0.051 & $0 \cdot 126$ \\
\hline Sp2 & 0.277 & 0.198 & 0.110 & 0.031 & 0.015 & $0 \cdot 126$ \\
\hline Sp3 & 0.173 & $0 \cdot 108$ & $0 \cdot 162$ & 0.046 & 0.041 & $0 \cdot 106$ \\
\hline $\ln 1$ & 0.306 & 0.068 & 0.145 & 0.065 & 0.079 & 0.133 \\
\hline $\ln 2$ & 0.324 & 0.224 & 0.238 & 0.021 & 0.024 & $0 \cdot 166$ \\
\hline $\ln 3$ & 0.320 & 0.237 & 0.304 & 0.035 & 0.033 & 0.186 \\
\hline $\ln 4$ & 0.296 & 0.297 & 0.319 & 0.041 & 0.043 & 0.199 \\
\hline $\ln 6$ & 0.255 & 0.219 & 0.261 & 0.094 & 0.059 & 0.178 \\
\hline Se1 & 0.270 & 0.147 & 0.112 & 0.025 & 0.027 & 0.116 \\
\hline $\mathrm{Se} 2$ & 0.346 & 0.319 & 0.157 & 0.068 & 0.021 & 0.182 \\
\hline $\mathrm{Se} 3$ & 0.300 & 0.326 & 0.156 & 0.062 & 0.065 & 0.182 \\
\hline Se4 & 0.312 & 0.249 & 0.098 & 0.044 & 0.100 & 0.161 \\
\hline Se 5 & 0.300 & 0.311 & 0.252 & $0 \cdot 102$ & 0.231 & 0.239 \\
\hline Se6 & 0.320 & 0.270 & 0.177 & 0.072 & 0.107 & 0.189 \\
\hline Se7 & 0.249 & 0.222 & 0.108 & 0.088 & 0.058 & 0.145 \\
\hline Se8 & 0.262 & 0.222 & 0.156 & 0.027 & 0.042 & $0 \cdot 142$ \\
\hline Se9 & 0.196 & 0.172 & 0.239 & 0.117 & 0.245 & 0.194 \\
\hline Se10 & $0 \cdot 187$ & 0.142 & 0.182 & $0 \cdot 103$ & 0.227 & 0.168 \\
\hline Total & 6.982 & 4.893 & $4 \cdot 181$ & $2 \cdot 810$ & $2 \cdot 590$ & $4 \cdot 291$ \\
\hline $\begin{array}{l}\text { Variance: } \\
\%\end{array}$ & $21 \cdot 902$ & $19 \cdot 611$ & $16 \cdot 780$ & $11 \cdot 222$ & $10 \cdot 453$ & $15 \cdot 994$ \\
\hline
\end{tabular}

Table 6. Measures of discrimination for Gothenburg central station

services (Se2), access to toilets (Se3) and access to internet (Se5). KQF2 was labelled 'services'.

The third dimension is highly associated with the possibility of buying different types of tickets at ticketing machines (In3) and from staff at counters (In4). KQF3 was thus labelled 'ticketing'.

Dimension 4 mainly relates to the coordination of timetables (Su1), possible travel connections between origin and destination (Su2), the possibility of combining different transport means for the journey (Su3) and the total waiting time (Ti4). KQF4 is thus associated with issues that enhance connections between means and the supply at the interchange. It was labelled 'transfer connectivity'.

The fifth dimension is associated with internet access (Se5), the provision of baby care facilities/play areas (Se9) and access to parking spaces (Se10). KQF5 was labelled 'additional facilities' since it is associated with issues that are important but not strictly necessary, and could be considered as plus values for the interchange.

Looking at the perceptual plot of dimensions 1 and 2, the level of satisfaction of the KQFs can be investigated, which together account for $41 \%$ of the variance (Figure 4 ).

As regards the axis of the first dimension, the lowest satisfaction ratings fall into the positive side, while the highest ratings fall into the negative area. Therefore, KQF1 (time) represents extremes of satisfaction: very low (1) or very high (5). The poles of axis 2 distinguish between medium/high satisfaction (3 and 4 respectively) on the positive side and very low/very high satisfaction on the negative side. KQF2 (services) has different perceptions among travellers. Table 7 summarises the level of satisfaction associated with the axes of the other dimensions. Travellers in Gothenburg central station have extreme perceptions of the KQFs and only KQF4 (connectivity) is skewed to low values.

\subsection{Comparison}

The analyses show that in both cases there are five KQFs explaining (summarising) travellers' perceptions of quality attributes. MCA provides two types of information - which are the perceived quality attributes and how are they perceived (i.e. the level of satisfaction). It is worth noting that in both cases the level of satisfaction with the QFKs was quite different among travellers, ranging from very low to very high ratings. Only ticketing in Madrid and connectivity in Gothenburg were skewed to low values, since the axes distinguish between medium and very low ratings (Tables 4 and 7).

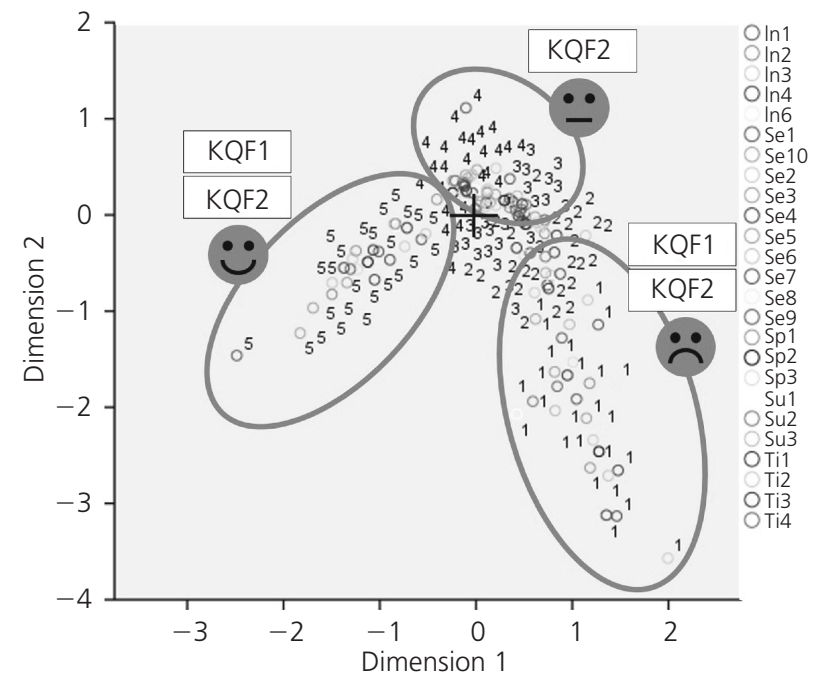

Figure 4. Gothenburg central station - perceptual plot KQF1KQF2 


\begin{tabular}{|c|c|c|c|c|}
\hline & \multirow{2}{*}{$\begin{array}{l}\text { Significant quality } \\
\text { attributes }\end{array}$} & \multirow[t]{2}{*}{ Label } & \multicolumn{2}{|c|}{ Level of satisfaction } \\
\hline & & & $\begin{array}{l}\text { Negative axis } \\
\text { of perceptual } \\
\text { plot }\end{array}$ & $\begin{array}{l}\text { Positive axis } \\
\text { of perceptual } \\
\text { plot }\end{array}$ \\
\hline KQF1 & Ti3, Ti4, In2, Se2 & Time & Very high & Very low \\
\hline KQF2 & $\mathrm{Se} 2, \mathrm{Se} 3, \mathrm{Se} 5$ & Services & Very low/very high & Medium/high \\
\hline KQF3 & $\ln 3, \ln 4$ & Ticketing & Very low/high & Medium \\
\hline KQF4 & Su1, Su2, Su3, Ti4 & $\begin{array}{l}\text { Transfer } \\
\text { connectivity }\end{array}$ & Medium & Very low \\
\hline KQF5 & Se5, Se9, Se10 & $\begin{array}{l}\text { Additional } \\
\text { facilities }\end{array}$ & Very high & Very low \\
\hline
\end{tabular}

Table 7. Summary of KQFs for Gothenburg central station

Ticketing plays a key role for both interchanges and the possibility of buying different types of tickets is crucial to passengers' perception of quality. However, differences were found from application of the methodology. Intermodal travellers in Madrid mainly perceived aspects related to the physical space, comfort and environmental conditions as important. On the contrary, in Gothenburg other aspects, such as temporal issues, the provision of services and interconnectivity among different means of transportation were perceived as important.

The differences can be explained in terms of the different contexts and traveller profiles. According to the survey in Madrid, regular travellers, travelling to visit friends, spend a considerable amount of time in the interchange. They thus need a comfortable and healthy place to wait for their next long-distance trip (by bus). According to the survey in Gothenburg, respondents are familiar with the interchange, spend a lot of time there and are travelling for shopping or business purposes. Their need is for a range of possibilities to link short and long trips. It is worth stressing that modal interconnectivity was perceived with different levels of satisfaction - low for shopping travellers and high for business travellers. This can be explained by the fact that shopping travellers are not regular users and tend to be more critical than regular business travellers, who are generally familiar with interconnectivity opportunities.

\section{Conclusion}

Travellers' perceptions of quality attributes were better understood through the KQFs identified through MCA in Madrid and Gothenburg. Ticketing plays a key role at both interchanges, being a necessary requirement of better interconnectivity in order to experience a seamless long-/short-distance journey (Bak, 2010; Rojo et al., 2011). Physical and environmental issues emerged in Madrid, in accordance with other studies where the space, the aesthetic and health environment of interchanges were found to be determinants in the use of public transport (Cascetta et al., 2013; Van Hagen, 2011). Services, temporal issues and intercon- nectivity emerged as important in Gothenburg, with contrasting perceptions because of different travellers' needs, confirming the complexity of timetable coordination and the importance of temporal aspects for interchanging commuters (Hutchinson, 2009; Stradling, 2002).

It is surprising that 'classical' issues such as safety/security and information did not emerge from the analysis in this study. This could be because safety/security are indirectly considered (integrated) in spatial and environmental issues (not isolated spaces, well-lit waiting rooms, etc.). Regarding information (understood as signage), this could be because efficient improvements have been introduced at the interchanges over the past few years, perhaps driven by the fact that information is often considered the main determinant for public transport quality (Grotenhuis et al., 2007).

This study holds some limitations since the customer satisfaction surveys were based on a simple random sampling plan and were conducted on weekdays - the perception of quality of transport interchanges at weekends may also influence the results. For example, the needs of commuters (or business users) and holiday travellers are different and this issue could not be considered in the analysis. Furthermore, the risk in these kinds of surveys, which are carried out on site through questionnaires, is to lose some information on positive aspects because respondents generally tend to focus on those factors that are wrong and need, in their view, changing. It is also worth pointing out that MCA is a descriptive/exploratory technique and thus the results are not useful by themselves for decision making or for making predictions, although they can provide a deep insight into the topic 'quality of service'.

The main outcome of the methodology used in this study was the identification of KQFs at urban interchanges. This can be considered as a starting point for further analyses and the development of policy macro-strategies. The approach is exploratory and 
additional research to clustering intermodal travellers should integrate the assessment of perceived quality at urban interchanges.

\section{Acknowledgements}

This study was possible thanks to data collected in the Hermes (High Efficient and Reliable arrangeMEnts for croSsmodal transport) project of the EU 7th Framework Programme under contract no. TCP8-GA-2009-234082. Thanks also go to Andrea Alonso, researcher at TRANSyT-UPM, for providing a coherent compilation of data.

\section{REFERENCES}

Aenor (2003) UNE-EN 13816: Transportation. Logistics and services. Public passenger transport. Service quality definition, targeting and measurement. Aenor, Madrid, Spain.

Bak M (2010) Integrated ticketing in passenger transport as a choice to improve interconnectivity. Proceedings of $12 \mathrm{th}$ World Conference on Transport Research, Lisbon, Portugal.

Bartlett JE, Kotrlik JW and Higgins C (2001) Organizational research: determining appropriate sample size for survey research. Information Technology, Learning, and Performance Journal 19(1): 43-50.

Beirão G and Sarsfield JA (2007) Understanding attitudes towards public transport and private car: a qualitative study. Transport Policy 14(6): 478-489.

Blow C (2005) Transport Terminals and Modal Interchanges Planning and Design. Architectural Press, Oxford, UK.

Bowers S (2011) All change? Motorway interchanges for public transport. Proceedings of the Institution of Civil Engineers Transport 164(4): 209-220.

Cascetta E, Carteni A and Carbone A (2013) La progettazione quality-based nel trasporto pubblico locale. Il sistema di metropolitana regionale della Campania. Ingegneria Ferroviaria 3(2013): 241-261 (in Italian).

City of Gothenburg (2012) RiverCity Gothenburg. Vision. City of Gothenburg, Gothenburg, Sweden.

CRTM (Consorcio Regional de Transportes de Madrid) (2010) Plan de Intercambiadores - Madrid. CRTM, Madrid, Spain.

Currie G (2005) The demand performance of bus rapid transit. Journal of Public Transportation 8(1): 41-55.

Dell'Asin G (2011) Methodology for the Assessment of Quality in Public Transport Interchanges. INECO, Madrid, Spain, Cuadernos de investigación del transporte 11-3.

Dell'Olio L, Ibeas A and Cecín P (2010) Modelling user perception of bus transit quality. Transport Policy 17(6): 388-397.

De Oña J, De Oña R and Calvo F (2012) A classification tree approach to identify key factors of transit service quality. Expert Systems with Applications 39(12): 11164-11171.

Eboli L and Mazzulla G (2007) Service quality attributes affecting customer satisfaction for bus transit. Journal of Public Transportation 10(3): 21-34.

Eboli L and Mazzulla G (2008) A stated preference experiment for measuring service quality in public transport. Transportation Planning and Technology 31(5): 509-523.

EC (European Commission) (2009) Efficiency in Sustainable Mobility - Thematic Research Summary. EC, Brussels, Belgium.

EC (European Commission) (2011) White Paper. Roadmap to a Single European Transport Area - Towards a Competitive and Resource Efficient Transport System. EC, Brussels, Belgium, COM(2011) 144 final.

Friman M (2004) Implementing quality improvements in public transport. Journal of Public Transportation 7(4): 49-65.

Greenacre M (2007) Correspondence Analysis in Practice, 2nd edn. Chapman \& Hall/CRC, Boca Raton, FL, USA.

Grotenhuis J, Wiegmans B and Rietveld P (2007) The desired quality of integrated multimodal travel information in public transport: customer needs for time and effort savings. Transport Policy 14(1): 27-38.

Hair JF, Anderson RE, Tatham RL and Black WC (2010) Multivariate Data Analysis, 7th edn. Pearson Prentice-Hall, Upper Saddle River, NJ, USA.

Hermes (2011) Hermes Project. Deliverable 5 - Case Studies. Transport Programme of the 7th RTD Framework Programme, Brussels, Belgium.

Hine J and Scott J (2000) Seamless, accessible travel: users' views of the public transport journey and interchange. Transport Policy 7(3): 217-226.

Hutchinson TP (2009) The customer experience when using public transport: a review. Proceedings of the Institution of Civil Engineers - Municipal Engineer 162(3): 149-157.

Lopez-Lambas ME and Monzón A (2010) Private funding and management for public interchanges in Madrid. Research in Transportation Economics 29(1): 323-328.

Morfoulaki M, Tyrinopoulos Y and Aifadopoulou G (2007) Estimation of satisfied customers in public transport systems: a new methodological approach. Journal of the Transportation Research Forum 46(1): 63-72.

Mulroy TM (2001) How do we make transport interchanges work? Proceedings of the Institution of Civil Engineers Municipal Engineer 145(1): 55-59.

Parasuraman A, Zeitlham VA and Berry LL (1985) A conceptual model of service quality and its implications for future research. Journal of Marketing 49(4): 41-50.

Paulley N, Balcombe R, Mackett R et al. (2006) The demand for public transport: the effects of fares, quality of service, income and car ownership. Transport Policy 13(4): 295-306.

Rojo M, Gonzalo-Orden H, Dell'Olio L and Ibeas A (2011) Modelling gender perception of quality in interurban bus services. Proceedings of the Institution of Civil Engineers Transport 164(1): 43-53.

Stradling SG (2002) Transport user needs and marketing public transport. Proceedings of the Institution of Civil Engineers Municipal Engineer 151(1): 23-28. 
Van Hagen M (2011) Effects of station improvement measures on customer satisfaction. Proceedings of the European Transport Conference, Glasgow, UK.
Vassallo JM, Di Ciommo F and García A (2012) Intermodal exchange stations in the city of Madrid. Transportation 39(5): 975-995.

\section{WHAT DO YOU THINK?}

To discuss this paper, please email up to 500 words to the editor at journals@ice.org.uk. Your contribution will be forwarded to the author(s) for a reply and, if considered appropriate by the editorial panel, will be published as a discussion in a future issue of the journal.

Proceedings journals rely entirely on contributions sent in by civil engineering professionals, academics and students. Papers should be $2000-5000$ words long (briefing papers should be 1000-2000 words long), with adequate illustrations and references. You can submit your paper online via www.icevirtuallibrary.com/content/journals, where you will also find detailed author guidelines. 